\title{
Article \\ Effects of Speciation, Cooking and Changes in Bioaccessibility on Methylmercury Exposure Assessment for Contrasting Diets of Fish and Marine Mammals
}

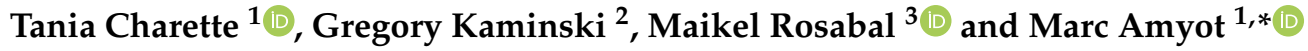 \\ 1 Groupe de Recherche Interuniversitaire en Limnologie (GRIL), Université de Montréal, Département de \\ Sciences Biologiques, Complexe des Sciences, C.P. 6128, succ. Centre-Ville, Montréal, QC H3C 3J7, Canada; \\ tania.charette@umontreal.ca \\ 2 Health Canada, 269 Laurier West, Ottawa, ON K1A 0K9, Canada; greg.kaminski@canada.ca \\ 3 Groupe de Recherche Interuniversitaire en Limnologie (GRIL), Département des Sciences Biologiques, \\ Université du Québec à Montréal (UQAM), 141 Avenue du Président-Kennedy, \\ Montreal, QC H2X 1Y4, Canada; rosabal.maikel@uqam.ca \\ * Correspondence: m.amyot@umontreal.ca
}

Citation: Charette, T.; Kaminski, G.; Rosabal, M.; Amyot, M. Effects of Speciation, Cooking and Changes in Bioaccessibility on Methylmercury Exposure Assessment for Contrasting Diets of Fish and Marine Mammals. Int. J. Environ. Res. Public Health 2021, 18, 2565. https://doi.org/10.3390/ ijerph18052565

Academic Editors: Ahmad Faizal Abdull Razis, Gergely Tóth and Paul B. Tchounwou

Received: 24 November 2020 Accepted: 23 February 2021 Published: 4 March 2021

Publisher's Note: MDPI stays neutral with regard to jurisdictional claims in published maps and institutional affiliations.

Copyright: (c) 2021 by the authors. Licensee MDPI, Basel, Switzerland. This article is an open access article distributed under the terms and conditions of the Creative Commons Attribution (CC BY) license (https:// creativecommons.org/licenses/by/ $4.0 /)$.

\begin{abstract}
Uptake of the neurotoxicant monomethylmercury ( $\mathrm{MeHg}$ ) from fish and marine mammals continues to present a public health concern in Canada and elsewhere. However, fish and marine mammals are key diet items contributing to food security for some Indigenous populations in Canada. Mercury $(\mathrm{Hg}$ ) exposure is estimated assuming that $100 \%$ of $\mathrm{Hg}$ is methylated, that $100 \%$ will be absorbed by the consumer and that cooking does not affect $\mathrm{MeHg}$ concentrations. Some of these assumptions do not correspond to our current state of knowledge. The aim of this study was to assess the impact of additional variables on $\mathrm{Hg}$ exposure equation using probabilistic risk analysis. New variables tested were (1) the proportion of methylated $\mathrm{Hg}$ compared to total $\mathrm{Hg}$ ( $\mathrm{pMeHg}, \%),(2)$ the relative absorption factor (RAF, \%) expressed as bioaccessibility and (3) the mass loss factor (MLF, unitless) that represents the loss of moisture during cooking, known to increase $\mathrm{MeHg}$ concentration in fish and mammals. For the new variables, data from literature were used in order to set point estimate values that were further used in the probabilistic risk analysis. Modelling results for both fish and marine mammals indicate that adding these new variables significantly influenced estimates of MeHg exposure (Mood's median test, $p<0.05$ ). This study highlights that the evaluation of exposure to $\mathrm{MeHg}$ is sensitive to $\mathrm{pMeHg}$, $\mathrm{RAF}$ and MLF, and the inclusion of these variables in risk assessment should be considered with care. Further research is needed to provide better food-dependent, population-specific estimates of RAF and MLF before formal inclusion in exposure estimates.
\end{abstract}

Keywords: methylmercury; exposure; fish; mammal; probabilistic

\section{Introduction}

Exposure to monomethylmercury (MeHg) from fish and marine mammals continues to present public health concerns in Canada and elsewhere [1,2]. This $\mathrm{Hg}$ chemical species is known for its ability to cross mammal blood-brain and placental barriers [3-5]. Studies have shown harmful neurological and neurodevelopmental effects due to $\mathrm{MeHg}$ exposure in babies and young children linked to maternal consumption of fish with elevated $\mathrm{MeHg}$ levels during pregnancy [6,7]. Populations consuming marine mammals are at greater risk, such as the Inuit population from Canada, since marine mammal meat and offal may contain high levels of $\mathrm{MeHg}$ and are often consumed [2]. A mean concentration of blood total $\mathrm{Hg}(\mathrm{THg})$ level of pregnant women from Nunavik was established at $4.2 \mu \mathrm{g} / \mathrm{L}$ (data from 2017) [8], compared to $0.6 \mu \mathrm{g} / \mathrm{L}$ for pregnant women from the general Canadian population (data from 2008 to 2011) [9]. 
Country food can be defined as « all food within a particular culture available from local natural resources and culturally accepted » [10]. Its consumption may present toxicological risks but remains desirable for several reasons. Country food consumption contributes to physical, mental, spiritual, emotional and social health in Indigenous populations [11]. Country foods are rich in proteins, vitamins, minerals and poor in saturated fats and sugars [12], which are key factors in preventing chronic diseases [11]. Furthermore, access to country food contributes to food security and helps to overcome lack of money for vulnerable households [13], since commercial food in the Canadian North is much more expensive than in the South [14].

In Canada, the consumption guidelines use a tolerable daily intake (TDI) as a basis for the calculation of allowable portion size and frequency of consumption [15]. Tolerable daily intake represents the reference dose $\left(\mu \mathrm{g} \times \mathrm{kg}^{-1}\right.$ body weight (bw) per day) for a noncarcinogenic compound that can be consumed daily over a lifetime without any harmful effects on human health [16]. This is based on the notion that harmful effects begin beyond a certain threshold [17]. Methylmercury TDIs determined by Health Canada are set at $0.2 \mu \mathrm{g} \times \mathrm{kg}^{-1}$ bw per day for sensitive populations (women of childbearing age and children $<12$ years) and $0.47 \mu \mathrm{g} \times \mathrm{kg}^{-1} \mathrm{bw}$ per day for the general adult population [15]. It is not identical worldwide: $\mathrm{WHO} / \mathrm{FAO}$ sets a benchmark dose of $0.23 \mu \mathrm{g} \times \mathrm{kg}^{-1} \mathrm{bw}$ per day [18], whereas U.S. EPA determined the threshold to be $0.1 \mu \mathrm{g} \times \mathrm{kg}^{-1}$ bw per day (including sensitive subgroup) [19].

The equations used by Health Canada [15] in the calculation of Hg exposure defined by the current model $(\mathrm{Ecm})$ and hazard quotient $(\mathrm{HQcm})$ are:

$$
\begin{gathered}
E c m=\frac{C R \times[T H g]}{B W} \\
H Q c m=\frac{E c m(\mathrm{mg} / \mathrm{kg} \text { bw per day })}{p T D I(\mathrm{mg} / \mathrm{kg} \text { bw per day })}
\end{gathered}
$$

where $C R$ represents the consumption rate (mg wet weight ( $\mathrm{ww}$ ) fish flesh per day), [THg] is the THg concentration in the fish flesh $\left(\mathrm{mg} \times \mathrm{kg}^{-1} \mathrm{ww}\right)$ and $B W$ is for body weight $(\mathrm{kg})$. Hazard quotient is used for threshold chemical compounds (non-carcinogenic), such as $\mathrm{MeHg}$ [16] and links the exposure and the potential risk [20]. HQ $\leq 1$ should not cause health effects, whereas HQ $>1$ could imply risks for exposed individuals. The assessment of $\mathrm{MeHg}$ exposure through food using Equation (1) implies that $100 \%$ of $\mathrm{Hg}$ is present as $\mathrm{MeHg}$. However, while the proportion of $\mathrm{MeHg}$ compared to $\mathrm{THg}$ is high in fish species $(>80 \%)$ [21], it is lower in marine mammal meat (range from 65 to $86 \%$ ) and offal (range from 8 to $26 \%$ ) [2]. Moreover, Equation (1) assumes that $100 \%$ of $\mathrm{MeHg}$ will be absorbed by the consumer, yet this assumption is based on a 1970s study, where humans were exposed to a solution of MeHg nitrate [22]. Furthermore, a growing number of in vitro digestion studies suggest that fish flesh cooking could decrease $\mathrm{MeHg}$ solubilization in digestive fluids (i.e., bioaccessibility), theoretically leading to a lower absorption rate [23-27].

At the moment Health Canada recommends a deterministic approach to assess $\mathrm{MeHg}$ exposure (see Equation (1)) through consumption pathways [15], involving the use of a point estimate value to describe each variable of Equation (1) neglecting the potential variability within population and uncertainties in the data [28]. In comparison, probabilistic analysis uses probability distributions defining one or more variables, accounting for the variability and uncertainties and resulting in a full range and frequency of hypothetical risks [28]. Often, upper-bound (worst-case scenario, 95th percentile) estimate variables are used in a deterministic approach to compensate for not taking the range of variability and data uncertainties into consideration. This also increases the confidence that risks have not been underestimated [15,29].

This paper aims to assess the impact of the inclusion of new variables in the $\mathrm{MeHg}$ exposure equation using probabilistic analysis. This analysis was performed for two consumption scenarios: Scenario 1 is based on the consumption patterns of the general Canadian population (consuming mostly salmon and albacore canned tuna) while scenario 
2 is based on consumption practices specific to many northern Indigenous populations (seal liver, beluga meat and beluga nikku). For scenario 1, we assessed MeHg exposure of the general population and of the sensitive part of the population, for medium $(22 \mathrm{~g} /$ day $)$ and high (40 g/day) consumption rates of fish. In scenario 2, we assessed the exposure to $\mathrm{MeHg}$ for the general Indigenous population and the sensitive part of this population, using consumption rates specific to each mammal species assessed.

We only considered fish and mammal meats as $\mathrm{MeHg}$ exposure pathways since other $\mathrm{MeHg}$ sources are considered negligible [30]. Furthermore, only $\mathrm{MeHg}$ was used in this risk assessment but it is known that fish and mammal muscles can contain other contaminants [31,32]. Thus, this study does not constitute a full human health risk assessment and was intended to be more of a sensitivity analysis. The goal of this paper is to test the exposure calculation by taking into account recent research. We consider that our study will serve as a starting point for practitioners and scientists to adjust currently used exposure equations, taking into consideration specific consumer groups and their diet. We do not propose any health-related changes in consumption guidelines, since we simply explore the potential effect of introducing new terms in exposure assessments, in order to guide future research.

\section{Materials and Methods}

\subsection{Population and Diet}

Our study compared MeHg exposure for two different dietary intake scenarios. Scenario 1 (Table 1) reflects the general Canadian diet and considers MeHg intake from salmon and canned tuna. Salmon (all species combined) was selected because it is the fish most consumed in Canada [15]. We also chose Albacore canned tuna containing generally relatively high $\mathrm{Hg}$ levels, and for which Health Canada issued consumption guidelines, in contrast to canned light tuna containing less $\mathrm{Hg}$ [33]. For the general and sensitive population, $\mathrm{CR}$ values and $\mathrm{THg}$ levels for salmon and canned tuna were obtained from Health Canada's publication [15], and BW from Canadian Exposure Factors Handbook [34] (Table 1). Scenario 2 (Table 1) reflects dietary consumption by the Indigenous Canadian population for which BW, CR and mass loss factor (MLF) data were obtained from Lemire et al. [2]. Lemire et al. based their data on the 2004 Nunavik Health Survey; we reevaluated the data on $\mathrm{MeHg}$ exposure for key marine mammal species using a probabilistic approach. The Indigenous BW value is a geometric mean $(n=702$, where women represent $48.2 \%)$ adjusted for age and gender, which could have overestimated the BW of the sensitive population in our modelling. THg concentration in marine mammals was obtained from Palaniyandi [35]. Beluga nikku (air-dried beluga meat) and seal liver were chosen to represent the marine mammal diet because they are the most Hg-contaminated part of the northern country diet $[2,35,36]$. In order to assess the effect of drying (MLF) on THg levels, beluga meat THg value was used in the modelling of risk assessment (Table 1). Note that scenario 2 is not meant to represent any specific community but rather aims to consider a diet rich in marine mammals. No inference to risk assessments of specific communities or populations should be derived from this theoretical exercise. The variables used in each scenario are described in detail in Table S1. 
Table 1. Values used in the probabilistic risk assessment.

\begin{tabular}{|c|c|c|c|c|c|c|c|}
\hline & \multirow[b]{2}{*}{ Input Variables } & \multicolumn{2}{|c|}{ Point Estimate } & \multicolumn{2}{|c|}{ Probability Distribution } & \multirow[b]{2}{*}{ Units } & \multirow[b]{2}{*}{ References } \\
\hline & & $\mathrm{CTE}^{\mathrm{a}}$ (SD) & $\mathrm{RMaE}^{\mathrm{b}}$ & $\begin{array}{c}\text { Distribution } \\
\text { Type }\end{array}$ & $\begin{array}{l}\text { Parameters } \\
\text { min;max }\end{array}$ & & \\
\hline \multirow{7}{*}{ CR } & Scenario 1-Fish flesh & & & & & & \\
\hline & Medium consumer & 22 & & & & g/day & [15] \\
\hline & High consumer & 40 & & & & g/day & [15] \\
\hline & Scenario 2-Marine mammals & & & & & & \\
\hline & Beluga meat (pre-drying) & 3.4 & & & & g/day & [2] \\
\hline & Beluga nikku & 2.3 & & & & $\mathrm{~g} /$ day & [2] \\
\hline & Seal liver & 1.0 & & & & g/day & [2] \\
\hline \multirow{4}{*}{ BW } & Scenario 1-Fish flesh & & & & & & \\
\hline & General population & $76.5(15.8)$ & 53.3 & lognormal & {$[40 ; 120]^{* * *}$} & $\mathrm{~kg}$ & [34] \\
\hline & Sensitive population & $69.8(16.3)$ & 46.5 & lognormal & {$[35 ; 115]^{* * *}$} & $\mathrm{~kg}$ & [34] \\
\hline & $\begin{array}{l}\text { Scenario 2-Marine mammals } \\
\text { Indigenous population }\end{array}$ & $68.4(20) *$ & 43.9 & lognormal & [38.2-129.4] & $\mathrm{kg}$ & [2] \\
\hline \multirow{6}{*}[\mathrm{THg}]{} & Scenario 1-Fish flesh & & & & & & \\
\hline & Salmon & $0.03(0.03) *$ & 0.07 & lognormal & [0-0.12] & ug/g (ww) & [15] \\
\hline & $\begin{array}{l}\text { Albacore canned tuna } \\
\text { Scenario 2-Marine mammals }\end{array}$ & $0.35(0.1)^{* *}$ & 0.5 & lognormal & {$[0.2-0.6]$} & $\mathrm{ug} / \mathrm{g}(\mathrm{ww})$ & [15] \\
\hline & Beluga meat (pre-drying) & $2.0(0.5)+$ & 30 & loonormal & {$[0.8-4.0]$} & $10 / \sigma(w W)$ & [35] \\
\hline & $\begin{array}{l}\text { Beluga nikku } \\
\text { Bello }\end{array}$ & $5.0(1.2)$ & 7.2 & lognormal & {$[2-10] * * *$} & $\mathrm{ug} / \mathrm{g}(\mathrm{ww})$ & [35] \\
\hline & Ringed seal liver & $19(11.1)$ & 23.7 & lognormal & {$[10-25]^{* * *}$} & $\mathrm{ug} / \mathrm{g}(\mathrm{ww})$ & [35] \\
\hline \multirow{4}{*}{$\mathrm{pMeHg}$} & Scenario 1-Fish flesh & & & & & & \\
\hline & Health authorities & 100 & & & & $\%$ & [15] \\
\hline & $\begin{array}{l}\text { Scenario 2-Marine mammals } \\
\text { Beluga meat }\end{array}$ & 65 & & & & $\%$ & [2] \\
\hline & Ringed seal liver & 11 & & & & $\%$ & {$[2]$} \\
\hline \multirow{7}{*}{ RAF } & Scenario 1-Fish flesh & & & & & & \\
\hline & Health authorities & 100 & & & & $\%$ & [15] \\
\hline & Cooked-In vitro & 40 & & & & $\%$ & {$[24,25,37,38]$} \\
\hline & $\begin{array}{l}\text { bioaccessibility } \\
\text { Scenario 2-Marine mammals }\end{array}$ & & & & & & \\
\hline & Beluga meat & 51 & & & & $\%$ & [35] \\
\hline & Beluga nikku & 33 & & & & $\%$ & {$[35,39]$} \\
\hline & Seal liver & 27 & & & & $\%$ & {$[35,39,40]$} \\
\hline \multirow{7}{*}{ MLF } & Scenario 1-Fish flesh & & & & & & \\
\hline & Salmon-all cooking methods & 1.35 & & & & unitless & [41-44] \\
\hline & Albacore canned tuna & 1 & & & & unitless & \\
\hline & Scenario 2-Marine mammals & & & & & & \\
\hline & Beluga meat (raw) & 1 & & & & unitless & [2] \\
\hline & Beluga nikku (Air-dried) & 2.5 & & & & unitless & [2] \\
\hline & Ringed seal liver (raw) & 1 & & & & unitless & [2] \\
\hline
\end{tabular}

${ }^{a}$ Central tendency exposure (CTE) expressed as arithmetic mean; ${ }^{b}$ Reasonable maximum exposure expressed as the 95th percentile of CTE; * arbitrary SD (no data available); ${ }^{* *}$ weighted average; ${ }^{* * *}$ arbitrarily truncated to remain realistic; $+[\mathrm{THg}]$ for beluga meat was estimated using the [THg] of beluga nikku divided by MLF; CR: consumption rate; BW: body weight; [THg]: THg concentration; pMeHg: proportion of THg that is methylated; RAF: relative absorption factor; MLF: mass loss factor.

\subsection{New Proposed Variables}

We tested an alternative model to the current Ecm model represented by Equations (1) and (2) using the following equation:

$$
E a m=\frac{C R \times[T H g] \times p M e H g \times R A F \times M L F}{B W}
$$

where Eam is the exposure estimate with the alternative model, $\mathrm{pMeHg}$ corresponds to the proportion (\%) of $\mathrm{THg}$ that is methylated in the tissue, $R A F$ relates to the relative absorption factor (RAF) (expressed as bioaccessibility, \%) and MLF means mass loss factor (MLF, unitless) in order to compensate for the moisture loss during cooking. Point estimates (central tendency exposure; CTE) were used in the modelling using Equation (3) (Table 1). For pMeHg in fish flesh, two values were used: 100\% (as the value currently used by health authorities [15]) and $90 \%$ as a value presented in the general literature (according to the European Food Safety Authority that reports 26 studies describing a mean range between $80 \%$ and $100 \%$ ) [30]. Values for beluga meat and seal liver were age-adjusted (16.5 and 6 years, respectively) based on a study by Lemire et al. [2]. For RAF values, we chose $100 \%$ (value used by default by health authorities, as they consider a 
complete absorption of $\mathrm{MeHg}$ ) [15] and $40 \%$ as a mean $\mathrm{MeHg}$ bioaccessibility reported in studies of cooked fish using different species, such as swordfish, grouper, tuna, salmon, common smooth-hound, Atlantic wreckfish, black scabbardfish, shark, tilapia, snapper, turbot and anchovy $[24,25,37,38]$. We allocated an RAF of $40 \%$ to canned tuna since it is cooked before being canned [45]. In the literature, the data on RAF for marine mammals are very scarce and no study was found describing the bioaccessibility of $\mathrm{MeHg}$ from this country's food. However, some studies have reported bioaccessibility of THg; an RAF of $51 \%$ was reported for beluga meat [35], and an average of 33\% for beluga nikku [35,39]. An average of $27 \%$ was associated with ringed seal liver $[35,39,40]$. In this study, bioaccessibility values were used since no in vivo study assessed the relative absorption of $\mathrm{MeHg}$ from cooked flesh. Finally, we included MLF in Equation (3) when appropriate in order to represent the loss of humidity during cooking, which is known to increase the $\mathrm{MeHg}$ concentration in fish flesh [37,41,46-48]. The value of 1.35 encompasses all cooking methods (grilling, frying, boiling, etc.) [37,41,46-48]. No MLF factor was added in the case of canned tuna that does not need further food processing before being eaten, and seal liver that is consumed raw [2]. The MLF for beluga nikku corresponds to the loss of moisture during air-drying of the beluga meat and was set at 2.5 [2].

The following equation was used to calculate the $\mathrm{CR}$ of canned tuna that would be allowed if HQ equals 1:

$$
C R \text { limit }=\frac{p T D I * B W * H Q}{[T H g] * p M e H g * R A F}
$$

\subsection{Probabilistic Risk Assessment}

For this study, CTE characterizes the mean whereas reasonable maximum exposure (RMaE) represents the 95th percentile of CTE (Table 1). Point estimate (CTE) values were used for the new parameters of Equation (3) (RAF, pMeHg and MLF) (Table 1). On the other hand, in order to account for the potential variability in the population (Table 1, BW) and uncertainties in the data (Table 1, [THg]), we developed a probabilistic risk assessment according to Health Canada [28] and U.S. EPA [29] procedures with R software [49], using a first-order Monte Carlo one-dimensional simulation $(n=10,000)$. Typically, 10,000 iterations are appropriate to capture most of the variability of the input distributions extremities [28]. The stability of the results was tested by varying the number of iterations from 10,000 to $10,000,000$ and similar results were obtained (Table S2). We generated lognormal distributions ( $n=10,000$, R: rlnormTrunc function from EnvStats package) for [THg] and BW with defined values based on literature (Table 1). According to Health Canada [28] and U.S. EPA [29], variables subject to the multiplicative effect of a large number of processes tend to yield a lognormal shape distribution. For Monte Carlo analysis, dependencies between variables were considered negligible. The only potential dependency that may occur is a positive correlation between the CR and the BW [15], but since they are positioned at both sides of the exposure equation (CR at the numerator and $\mathrm{BW}$ at the denominator, see Equations (2) and (3)) this limits the bias caused by this dependency.

\subsection{Impact of RAF on Risk Estimates}

To illustrate the impact of MeHg bioaccessibility on the level of estimated risk (expressed as HQ; we extracted data from various studies [37,50-55]. We used the values of $\mathrm{MeHg}$ bioaccessibility and $\mathrm{MeHg}$ initial concentration in fish muscle in order to calculate the resulting HQ. Equation (1) (CR-medium consumption and BW of the general population, Table 1) with the addition of RAF was applied in the modelling.

\subsection{Statistic and Icons}

The resulting HQ distributions were summarized with box-and-whisker plots. When needed, HQ distributions were compared with Mood's median test. Significance level was set at $\alpha<0.05$. Seal and beluga icons were downloaded from the noun project 
(www.thenounproject.com; accessed on 5 January 2021), from Victoruler, Valeriia Vlasovtseva artists, ProSymbols and Rfourtytwo.

\section{Results}

\subsection{The Impact of the Proposed Variables on Methylmercury Exposure}

Table 2 summarizes the $\mathrm{MeHg}$ daily exposure dose as a function of diet, $\mathrm{CR}$ and $\mathrm{BW}$ for each scenario, and the impact of adding a single variable in a stepwise way to the exposure equation. Only albacore canned tuna results are presented since salmon did not produce exposure superior to TDI. The use of the current model (Equation (1)) for the Canadian non-Indigenous population, led to estimates of daily doses below the TDI of $0.47 \mu \mathrm{g} \times \mathrm{kg}^{-1} \mathrm{bw}$ per day for the general adult population. The addition of each single variable led to an exposure distribution significantly different from $\mathrm{Ecm}$.

The TDI for sensitive population (women of childbearing age and children $<12$ years) is $0.2 \mu \mathrm{g} \times \mathrm{kg}^{-1}$ bw per day and this value was exceeded by $4 \%$ and $50 \%$ of the population regarding the canned tuna scenario for the medium and high consumption rate respectively, when using the current model (see Equation (1)). In the high consumption rate scenario, the addition of $\mathrm{pMeHg}$ and RAF decreased the percentage of the population exceeding the TDI by $12 \%$ and $50 \%$, respectively. For this scenario, the use of the alternative model led to a safe $\mathrm{MeHg}$ exposure in $99.9 \%$ of cases. For the seal liver scenario, the addition of either $\mathrm{pMeHg}$ or RAF decreased the percentage of at-risk populations to zero \%, in comparison to the TDI obtained with the current model (see Equation (1)) which led to $2.7 \%$ of the at-risk population. For the beluga nikku, $0.1 \%$ of the population exceeds the TDI when MLF is considered. Overall, while pMeHg and RAF lead to a decrease in exposure, MLF increases it. These results suggest that the proposed variables ( $\mathrm{pMeHg}$, RAF and MLF) should be considered in exposure modelling by health authorities.

\subsection{Risk Characterization}

In order to assess the impact of the proposed variables on the health risk from $\mathrm{MeHg}$ exposure, we compared the HQ distributions obtained using Ecm vs. Eam. As observed in Figures 1 and 2, the simultaneous addition of all proposed variables (pMeHg, RAF and MLF) systematically led to a decrease of MeHg risk exposure.

\subsubsection{Salmon and Canned Tuna Consumption Scenario}

Figure 1 shows the HQ distribution as a function of the fish species consumed frequently and as a function of the variables used in the assessment of $\mathrm{MeHg}$ exposure, for the general and sensitive Canadian population. According to Figure 1, salmon consumption should not cause any health risk; using the current model we estimated HQ (median) to be between 0.01 and 0.03 for the general and the sensitive population, respectively, (Table S3). On the other hand, the consumption of canned tuna by the sensitive Canadian general population using the current model (see Equation (1)) led to $H Q>1$ for $50 \%$ of the population (Table S3), whereas the addition of pMeHg and RAF into the assessment produced an HQ distribution where $99.9 \%$ of the population was not exposed to any risks $(\mathrm{HQ}<1)$.

\subsubsection{Marine Mammal Consumption Scenario}

Figure 2 illustrates the health risks associated with $\mathrm{MeHg}$ exposure through marine mammal consumption with the example of the sensitive Indigenous population. In the case of the seal liver, which is consumed raw, the current model (see Equation (1)) led to $\mathrm{HQ}>1$ in $69 \%$ of cases, whereas the addition of pMeHg produced an HQ above 1 in 100\% of cases (Table S3). Regarding the beluga meat and nikku, the use of the current model (see Equation (1)) produced HQ > 1 for $1.9 \%$ and $0.01 \%$ of the population, respectively). 
Table 2. Independent impact of adding a single variable in the equation of the exposure of $\mathrm{MeHg}$. Results are expressed as median of $\mathrm{MeHg}$ daily exposure dose $\left(\mu \mathrm{g} \times \mathrm{kg}^{-1} \mathrm{bw}\right)$ and the percentage of the distribution of exposure that exceeds the TDI value is in parentheses (no number signifies $0 \%$ ). Alternative model shows the resulting $\mathrm{MeHg}$ daily exposure when all the proposed variables are integrated simultaneously into the exposure equation. See Table S1 for the details on variables used for each scenario. * are used to indicate a significative difference $(p<0.05)$ between the exposure distribution compared to the current model. pMeHg: proportion of THg that is methylated; RAF: relative absorption factor; MLF: mass loss factor.

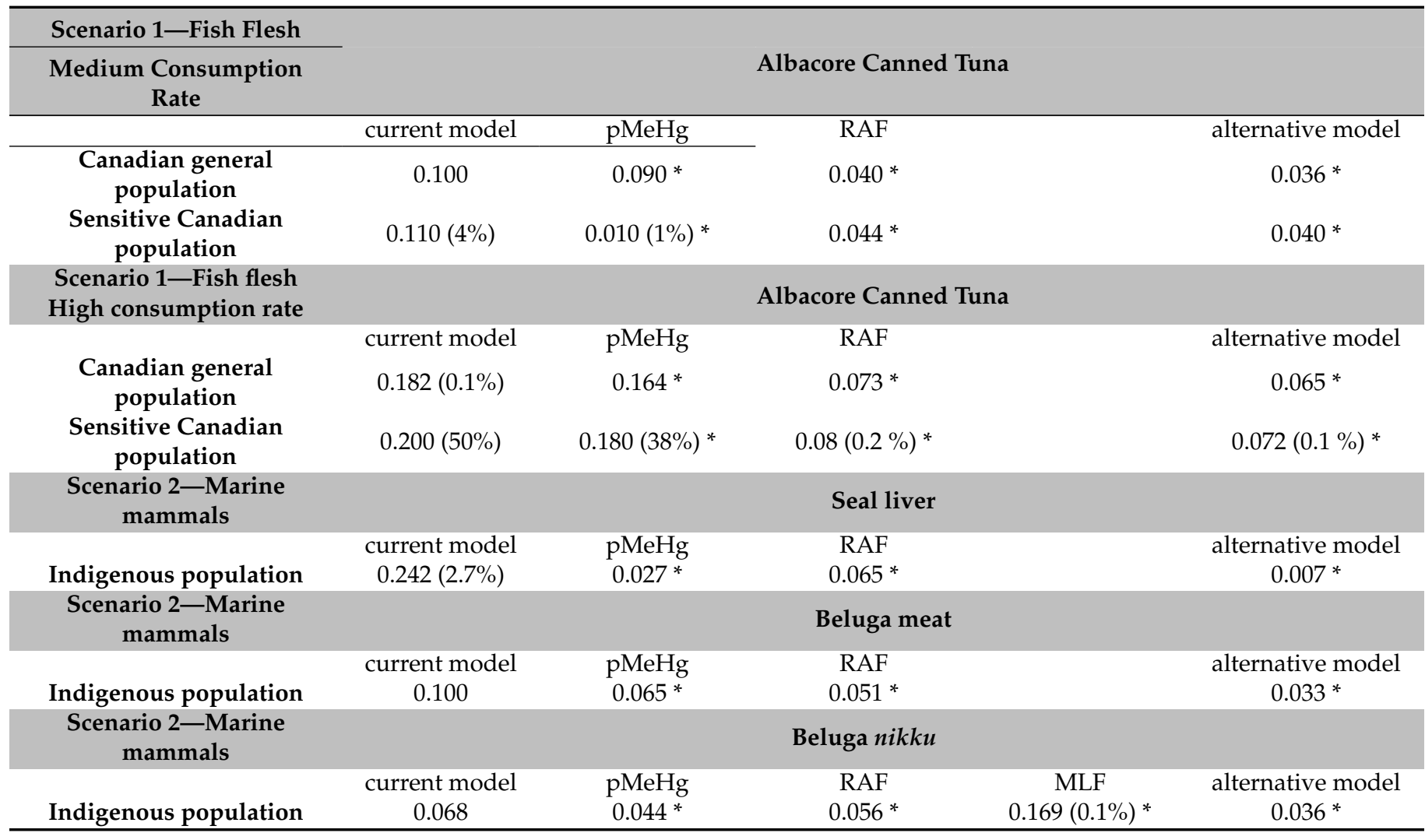

\subsection{The Implication of RAF in Methylmercury Risk Characterization}

We explored the relationship between RAF (expressed as bioaccessibility, \%) and HQ, to assess the effect of cooking on $\mathrm{HQ}$, since cooking has been shown to decrease the $\mathrm{MeHg}$ bioaccessibility in in vitro studies [23-26]. Figure 3 was created using the values $(n=45)$ of seven studies that have assessed the effect of cooking on $\mathrm{MeHg}$ bioaccessibility in the flesh of various fish [37,50-55]. Methylmercury exposure used to estimate HQ was calculated using the CR-medium consumption and BW of the general population (Table 1), the initial $\mathrm{MeHg}$ level in fish flesh and their respective bioaccessibility. Hence, we used the current model + RAF. As mathematically expected, HQ is linearly related to the bioaccessibility (raw: $r^{2}=0.50, p<0.05$; cooked: $r^{2}=0.35, p<0.05$ ). According to Figure 3 , the risk related to the consumption of cooked fish is higher than for raw fish, which is associated with higher $\mathrm{MeHg}$ levels in species chosen for the assessment of the effect of cooking on bioaccessibility. It is noteworthy that for a given fish species, bioaccessibility may largely vary. 

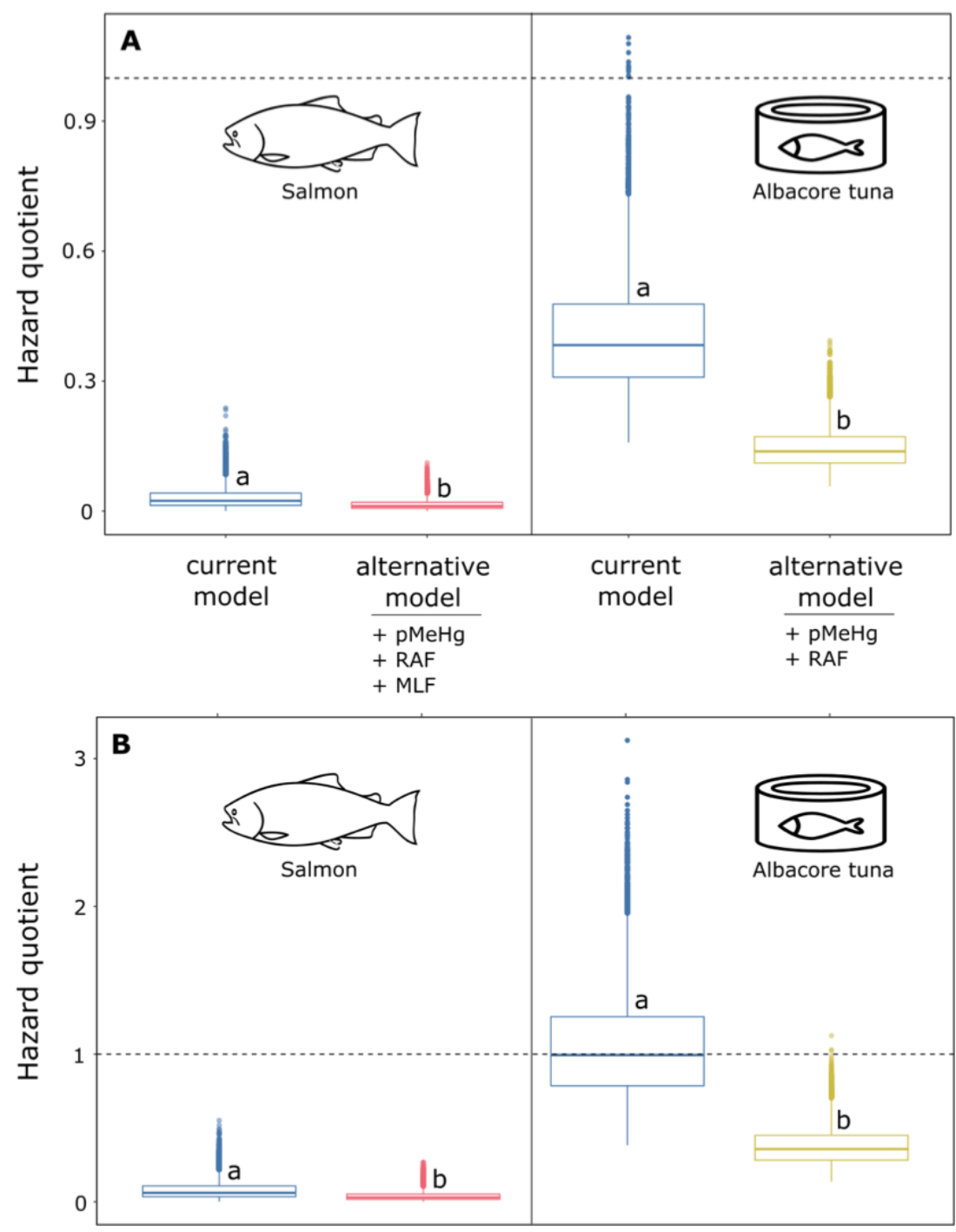

Figure 1. Hazard quotient as function of the fish species consumed and as function of the variables used in the assessment of $\mathrm{MeHg}$ exposure. High consumption rate scenario was used. (A) Canadian general population and (B) sensitive Canadian general population. Letters are used to indicate a significative difference $(p<0.05)$ between HQ distribution of a given fish species. See Table S1 for the details of variables used for each scenario. pMeHg: proportion of $\mathrm{THg}$ that is methylated; RAF: relative absorption factor; MLF: mass loss factor. 

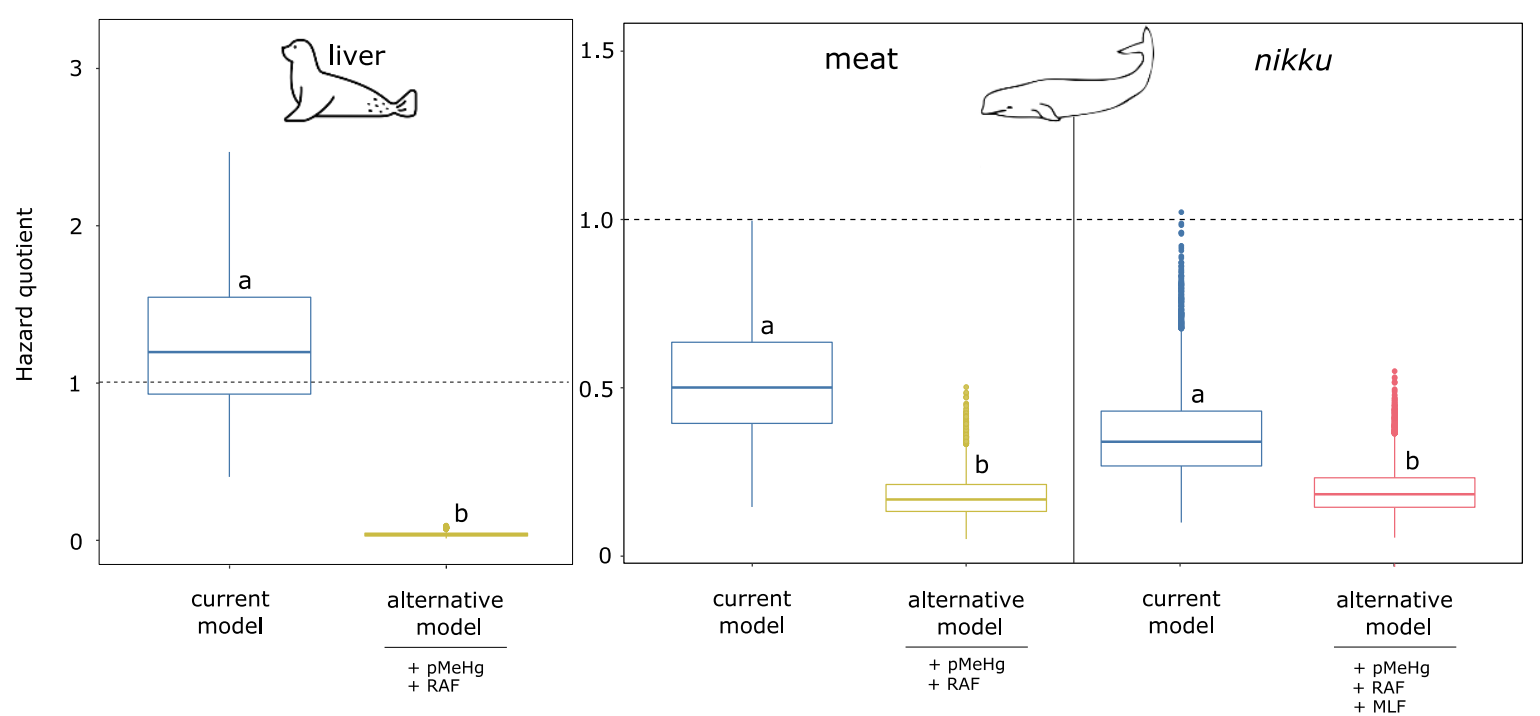

Figure 2. Hazard quotient as function of marine mammals consumed and as function of the variables used in the assessment of $\mathrm{MeHg}$ exposure for the sensitive Indigenous population. Letters are used to indicate a significative difference $(p<0.05)$ between a given scenario. See Table S1 for the details of variables used for each scenario. pMeHg: proportion of THg that is methylated; RAF: relative absorption factor; MLF: mass loss factor.

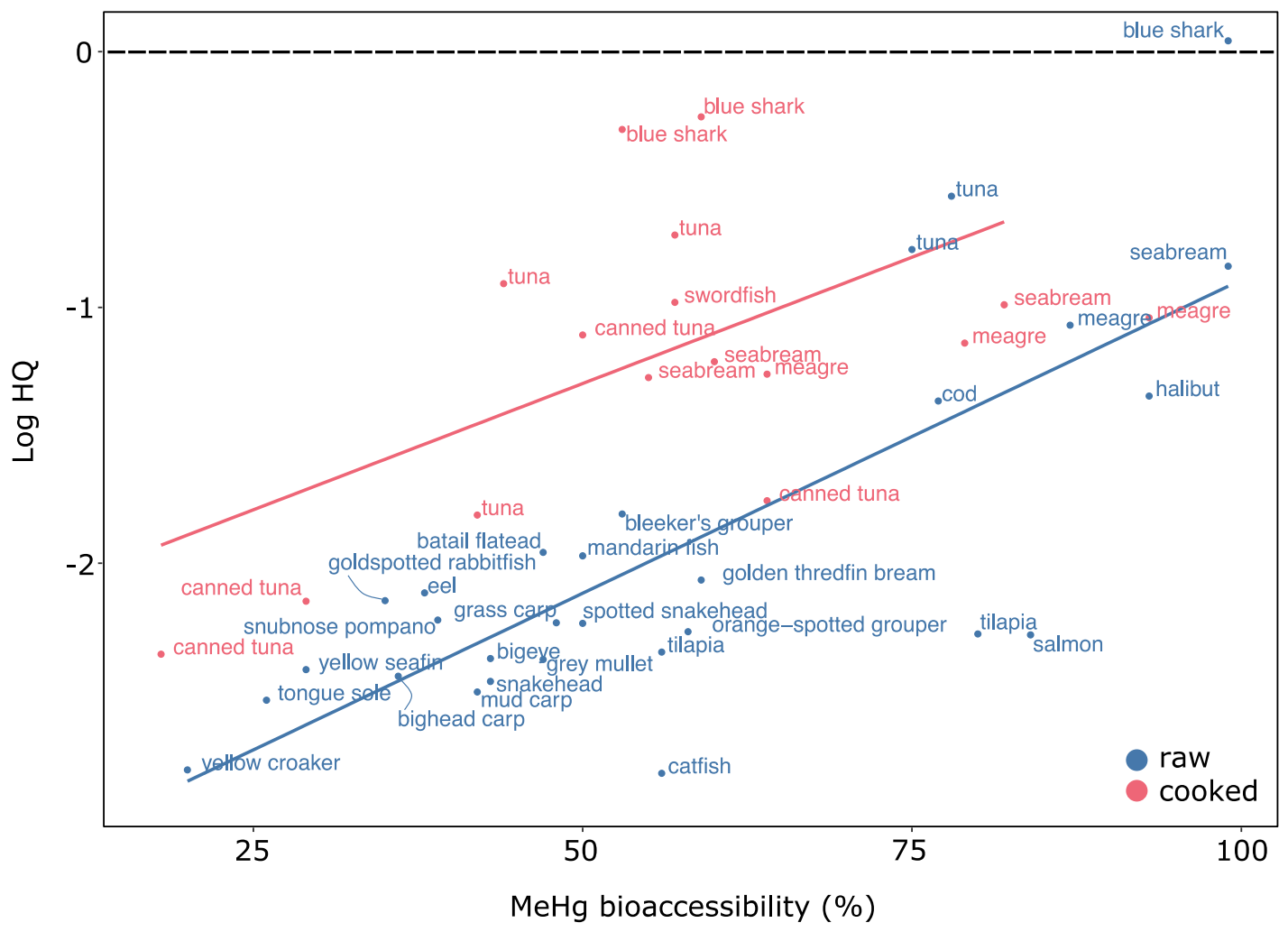

Figure 3. Impact of RAF (expressed as bioaccessibility, \%) on HQ. Blue for the raw bioaccessibility value and pink for the cooked one. Dotted line represents $\mathrm{HQ}=1$. HQ was assessed using the CR-medium consumption and BW of the general population (Table 1). The initial MeHg level in fish flesh and their respective bioaccessibility were obtained from: [37,50-55]. 


\section{Discussion}

\subsection{The Proposed Model Modifications Impact Methylmercury Exposure Assessment}

In all cases, every suggested variable significantly impacted $\mathrm{MeHg}$ daily dose exposure compared to the current model (see Equation (1)) (Table 2). For instance, according to Health Canada guidelines, sensitive members of the population should limit their consumption of albacore canned tuna to $300 \mathrm{~g}$ per week [33], which is seven times less than the quantity that could be allowed when the proposed variables are included in the assessment of $\mathrm{MeHg}$ exposure (see Equation (4), data not shown). This study, therefore, highlights the importance of carefully considering the proposed variables in $\mathrm{MeHg}$ exposure assessment and the need to better estimate these variables with care.

The value of $90 \%$ used for the $\mathrm{pMeHg}$ (Table 1 ) for fish flesh is still quite conservative since pMeHg tends to vary according to the trophic level, feeding habits and age. Lescord et al. [56] found a pMeHg range from 40 to $100 \%$ in Canadian fish flesh, and this is in agreement with the conclusion of the Evaluations of the Joint FAO/WHO Expert Committee on Food Additives (JECFA) who provided a range between $30 \%$ and 100\% [7]. The value of $\mathrm{pMeHg}$ for marine mammals varies in literature as well. For instance, values for beluga muscle pMeHg range from 65 to $97 \%[2,57,58]$. Our study may underestimate $\mathrm{MeHg}$ exposure since we chose the inferior value of this range (Table 1). In seal liver, literature shows that $\mathrm{pMeHg}$ can be as low as $2.7 \%$ and is known to decrease with the age of the seal [58], complexifying the assessment of $\mathrm{MeHg}$ exposure.

Another variable that we suggest adding in the assessment of $\mathrm{MeHg}$ exposure is RAF, which decreased significantly the exposure of $\mathrm{MeHg}$ (Table 2, Figure 3). Bioaccessibility studies have demonstrated that $\mathrm{MeHg}$ solubility decreased with fish flesh cooking $[24,25,37,38]$. However, it is important to note that bioaccessibility values are notoriously variable with low inter-laboratory or even intra-laboratory reproducibility, and the lack of use of standardized protocol leads to a wide range of values [25]. Additionally, the impact of cooking on $\mathrm{MeHg}$ oral bioavailability was assessed using pigs and it was suggested that cooking fish muscle did not modify $\mathrm{MeHg}$ oral bioavailability [59]. Hence, currently, in vitro and in vivo results diverge.

A standardized in vitro digestion protocol was developed by the COST INFOGEST network, in which skim milk powder protein digestibility was validated using pig models [60]. Once optimized for metals, this model protocol could be used as a starting point to standardize in vitro protocols for $\mathrm{MeHg}$ bioaccessibility studies, since $\mathrm{MeHg}$ is mostly bound to proteins. It could also be used for the assessment and validation of in vitro digestibility of raw and cooked fish flesh.

Presently, we do not recommend using bioaccessibility (i.e., RAF) estimates in the assessment of MeHg exposure, since it could significantly underestimate the exposure of the consumer without sufficiently strong scientific evidence. Additionally, since pMeHg highly varies in country foods [2], THg bioaccessibility could be a weak proxy of bioaccessibility of MeHg. Standardization and in vivo validation are needed before RAF is included in the alternative model.

The last variable studied was MLF. While there is no consensus regarding the impact of cooking on MeHg levels, the majority of studies point in the direction of an increase of $\mathrm{MeHg}$ concentration due to mass loss linked to water loss during cooking [37,41,46-48]. Including MLF in the model increases drastically the daily exposure to $\mathrm{MeHg}$, but on the other hand, according to bioaccessibility literature, cooking $[24,25,37,38]$ and drying $[35,39]$ can decrease the solubilization of $\mathrm{MeHg}$ and $\mathrm{THg}$ during digestion. The interaction between those phenomena should be further investigated by researchers and health authorities.

Our findings show that there is a great range of values for the proposed variables presented in this study (pMeHg, MLF and RAF), but does not address the inter-population variability regarding $\mathrm{BW}$ and $\mathrm{CR}$, nor the potential heterogeneity of $\mathrm{MeHg}$ distribution within fish muscle [61]. Many of these variables (BW, CR and [THg]) vary geographically and culturally, which makes the assessment of exposure to $\mathrm{MeHg}$ through diet difficult. 
This emphasizes the importance of the probabilistic risk assessment approach, where uncertainties and inter-population variability of data are included in the assessment [28].

\subsection{The Assessment of Methylmecury Exposure through Marine Mammals Should Be a Priority}

Health Canada has stated that for $\mathrm{MeHg}$ exposure from food the 95th percentile dose estimate obtained from probabilistic risk assessment should produce $\mathrm{HQ}<1$ [62]. Our results indicate that the inclusion of some of the proposed variables could modify the HQ for Indigenous consumers and particularly for those who consume seal liver and beluga meat (Table S3). Better assessing the values of $\mathrm{pMeHg}, \mathrm{MLF}$ and RAF for foods rich in $\mathrm{MeHg}$ would allow for better estimates of risk and more precise consumption advisories. Presently local health services in many Canadian provinces and Territories (such as the Nunavik Regional Board of Health and Social Services (www.nrbhss.ca; accessed on 22 January 2021)) encourage the consumption of country food as a good source of nutrients but recommend that pregnant women and women of childbearing age limit their consumption of beluga meat.

Assessing exposure to $\mathrm{MeHg}$ through country food consumption is complex as it depends on personal consumption patterns, seasonal food availability [63] and variability of $\mathrm{MeHg}$ content in different tissues of country foods [2,58,61].

We must underline that a calculated $H Q>1$ not necessarily leads to imminent health risks. Health Canada in its calculations of TDIs, included an uncertainty factor (UF) to account for inter-individual variability and to derive safe guidelines [64]. The TDI for the general population is based on $\mathrm{Hg}$ blood levels with no observable harmful effect from MeHg poisoning cases in Japan (1950-1960) and Iraq (1970), to which a UF of 10 was added [64]. For the sensitive population, the TDI comes from the data of three epidemiological studies conducted in the Seychelles and Faroes Island and New Zealand which assessed the effect of exposure to $\mathrm{MeHg}$ in utero on fetal neurodevelopment [64]. In this context, Health Canada used the MeHg level in maternal hair with no observable harmful effect, which was further converted into blood levels. A UF of 5 was added in order to produce the TDI [64]. Thus, HQ slightly higher to 1 will very unlikely lead to health risks. However, how far HQ can be exceeded without risks? At the moment, science does not allow an answer to this question.

Our study focused on $\mathrm{MeHg}$ exposure. However, balancing risks and benefits regarding country food consumption is essential and is not a trivial task since many benefits have to be considered. First, food scarcity, anemia and obesity are significant health issues for some communities in Canada, and country food brings many key nutrients that are needed to improve health. Lemire et al. [2] found that most of the commonly consumed country food in Nunavik (Canada) are poor in MeHg and rich in selenium (Se), with the exception of beluga meat and seal liver.

Further, country food consumption has also social dimensions (ex. socio-cultural and spiritual) that are usually assessed qualitatively, while health risks are measured quantitatively (ex. contaminant concentration) [65]. An overall assessment of risks and benefits requires the involvement of many disciplines such as nutrition, toxicology, sociology and public health practice [66]. Furthermore, risks and benefits can vary as a function of multiple factors, such as animal size, species, origin (aquaculture or wild), contamination, seasonal changes in consumption rates (g/day), consumer profile (age and gender) and more [7].

\section{Conclusions}

Overall, our study demonstrated the sensitivity of the MeHg exposure assessment and underlined the need to deepen our knowledge of the additional, suggested variables in order to avoid an underestimation or overestimation of the risk. Of particular importance is the need to better investigate bioaccessibility before RAF is included in a new risk assessment model. 
We showed that pMeHg and RAF decreased MeHg exposure, while MLF increased it. Salmon consumption produced $\mathrm{HQ}<1$ in all cases, while the consumption of Albacore canned tuna resulted in HQ $>1$ for the Canadian sensitive population, mostly when highrate consumption is assessed. Methylmercury exposure through seal liver consumption should be investigated, since our modelling shows a great difference between the current and the alternative model. Furthermore, even though beluga nikku is more contaminated than beluga meat, its lesser bioaccessibility could buffer this difference and lead to similar $\mathrm{MeHg}$ exposure. However, validation of in vitro studies should be conducted before proposing changes in consumption guidelines.

Finally, benefits are to be considered before setting recommendations.

Supplementary Materials: The following are available online at https:/ /www.mdpi.com/1660-460 1/18/5/2565/s1, Table S1: Details of the variables used in the modelling of each scenario, Table S2: Stability of the simulations obtained by varying the number of iterations. High consumption rate of canned tuna scenario for the general population was used, Table S3: Resulting median HQ using the current and the alternative model for the general and the sensitive population (see Figures 1 and 2). The percentage of the distribution of $H Q>1$ is in parentheses (no number signifies $0 \%$ ).

Author Contributions: T.C., G.K. and M.A.; methodology, T.C.; formal analysis, T.C.; writingoriginal draft preparation, T.C.; writing-review and editing, M.A., G.K. and M.R.; visualization, T.C.; supervision, M.A. and M.R.; funding acquisition, G.K. and M.A. All authors have read and agreed to the published version of the manuscript.

Funding: Research was funded through the Canada Research Chair program (M.A.), NSERC Discovery grants (M.A., M.R.) and an NSERC CREATE Ecolac stipend to T.C.

Institutional Review Board Statement: Not applicable.

Informed Consent Statement: Not applicable.

Data Availability Statement: Data sharing not applicable. No new data were created or analyzed in this study. Data sharing is not applicable to this article.

Acknowledgments: The author thanks Kevin Charette for statistical advice and Mélanie Lemire for comments on the manuscript.

Conflicts of Interest: The authors declare no conflict of interest.

\section{References}

1. Joint Expert Committee on Food Additives (JECFA). Safety Evaluation of Certain Food Additives and Contaminants; WHO: Geneva, Switzerland, 2004.

2. Lemire, M.; Kwan, M.; Laouan-Sidi, A.E.; Muckle, G.; Pirkle, C.; Ayotte, P.; Dewailly, E. Local country food sources of methylmercury, selenium and omega-3 fatty acids in Nunavik, Northern Quebec. Sci. Total Environ. 2015, 509-510, 248-259. [CrossRef]

3. Amin-Zaki, L.; Elhassani, S.; Majeed, M.A.; Clarkson, T.W.; Doherty, R.A.; Greenwood, M. Intra-uterine Methylmercury Poisoning in Iraq. In Problems of Birth Defects; Springer International Publishing: Berlin, Germany, 1974; pp. 233-241.

4. Aschner, M.; Aschner, J.L. Mercury neurotoxicity: Mechanisms of blood-brain barrier transport. Neurosci. Biobehav. Rev. 1990, 14, 169-176. [CrossRef]

5. Kerper, L.E.; Ballatori, N.; Clarkson, T.W. Methylmercury transport across the blood-brain barrier by an amino acid carrier. Am. J. Physiol. Integr. Comp. Physiol. 1992, 262, 761-765. [CrossRef]

6. Cohen, J.T.; Bellinger, D.C.; Shaywitz, B.A. A quantitative analysis of prenatal methyl mercury exposure and cognitive development. Am. J. Prev. Med. 2005, 29. [CrossRef]

7. FAO/WHO. Report of the Joint FAO / WHO Expert Consultation on the Risks and Benefits of Fish Consumption; FAO: Rome, Italy, 2010; Volume FIPM.

8. Adamou, T.Y.; Riva, M.; Muckle, G.; Laouan Sidi, E.A.; Lemire, M.; Ayotte, P. Blood mercury and plasma polychlorinated biphenyls concentrations in pregnant Inuit women from Nunavik: Temporal trends, 1992-2017. Sci. Total Environ. 2020, 743. [CrossRef]

9. Arbuckle, T.E.; Liang, C.L.; Morisset, A.S.; Fisher, M.; Weiler, H.; Cirtiu, C.M.; Legrand, M.; Davis, K.; Ettinger, A.S.; Fraser, W.D. Maternal and fetal exposure to cadmium, lead, manganese and mercury: The MIREC study. Chemosphere 2016, 163, 270-282. [CrossRef]

10. Kuhnlein, H.V.; Receveur, O. Dietary change and traditional food systems of Indigenous Peoples. Annu. Rev. Nutr. 1996, 16, 417-442. [CrossRef] [PubMed] 
11. Council of Canadian Academies. Aboriginal Food Security in Northern Canada: An Assessment of the State of Knowledge; Council of Canadian Academies: Ottawa, ON, Canada, 2014.

12. Kuhnlein, H.V.; Appavoo, D.; Morrison, N.; Soueida, R.; Pierrot, P. Use and nutrient composition of traditional sahtú (Hareskin) dene/métis foods. J. Food Compos. Anal. 1994, 7, 144-157. [CrossRef]

13. Van Oostdam, J.; Gilman, A.; Dewailly, E.; Usher, P.; Wheatley, B. Human health implications of environmental contaminants in Arctic Canada: A review. Sci. Total Environ. 1999, 230, 1-82. [CrossRef]

14. Chan, H.M.; Fediuk, K.; Hamilton, S.; Rostas, L.; Caughey, A.; Kuhnlein, H.; Egeland, G.; Loring, E.; Man, H.; Fediuk, K.; et al. Food security in Nunavut, Canada: Barriers and recommendations. Int. J. Circumpolar Health 2006, 65, 416-431. [CrossRef]

15. Health Canada. Human Health Risk Assessment of Mercury in Fish and Health Benefits of Fish Consumption; Health Canada: Ottawa, ON, Canada, 2007.

16. Rice, G.; Swartout, J.; Mahaffey, K.; Schoeny, R. Issues in risk assessment of chemicals of concern to department of defense and other agencies session: Derivation of U.S EPA's oral reference dose (RFD) for methylmercury. Drug Chem. Toxicol. 2000, 23, 41-54. [CrossRef]

17. United States Environmental Protection Agency (US EPA). IRIS Assessment Plan for Methylmercury; EPA: Washington, DC, USA, 2019.

18. Joint FAO/WHO Expert Committee. Food Additives and Contaminants. Sixty-First Meeting. Summary and Conclusions; WHO: Geneva, Switzerland, 2003.

19. United States Environmental Protection Agency (US EPA). Mercury Study Report to Congress—Volume I: Executive Summary; EPA: Washington, DC, USA, 1997.

20. McAuley, C.; Smith, D.; Dersch, A.; Koppe, B.; Mouille-Malbeuf, S.; Sowan, D. Whole fish vs. fish fillet-The risk implications for First Nation subsistence consumers. Cogent Food Agric. 2018, 4, 1-12. [CrossRef]

21. Magalhães, M.C.; Costa, V.; Menezes, G.M.; Pinho, M.R.; Santos, R.S.; Monteiro, L.R. Intra- and inter-specific variability in total and methylmercury bioaccumulation by eight marine fish species from the Azores. Mar. Pollut. Bull. 2007, 54, 1654-1662. [CrossRef]

22. Aberg, B.; Ekman, L.; Falk, R.; Greitz, U.; Persson, G.; Snihs, J.O. Metabolism of methyl mercury (203Hg) compounds in man. Arch. Environ. Health 1969, 19, 478-484. [CrossRef]

23. Alves, R.N.; Maulvault, A.L.; Barbosa, V.L.; Fernandez-Tejedor, M.; Tediosi, A.; Kotterman, M.; van den Heuvel, F.H.M.; Robbens, J.; Fernandes, J.O.; Romme Rasmussen, R.; et al. Oral bioaccessibility of toxic and essential elements in raw and cooked commercial seafood species available in European markets. Food Chem. 2018, 267, 15-27. [CrossRef]

24. Anacleto, P.; Barbosa, V.; Alves, R.N.; Maulvault, A.L.; Bronze, M.R.; Marques, A. Green tea infusion reduces mercury bioaccessibility and dietary exposure from raw and cooked fish. Food Chem. Toxicol. 2020, 145, 135577. [CrossRef] [PubMed]

25. Girard, C.; Charette, T.; Leclerc, M.; Shapiro, B.J.; Amyot, M. Cooking and co-ingested polyphenols reduce in vitro methylmercury bioaccessibility from fish and may alter exposure in humans. Sci. Total Environ. 2017, 616-617, 863-874. [CrossRef] [PubMed]

26. Torres-Escribano, S.; Velez, D.; Montoro, R.; Vélez, D.; Montoro, R. Mercury and methylmercury bioaccessibility in swordfish. Food Addit. Contam. Part a-Chemistry Anal. Control Expo. Risk Assess. 2010, 27, 327-337. [CrossRef] [PubMed]

27. Bradley, M.; Barst, B.; Basu, N. A review of mercury bioavailability in humans and fish. Int. J. Environ. Res. Public Health 2017, 14, 169. [CrossRef]

28. Health Canada. Federal Contaminated Site Risk Assessment in Canada Part V: Guidance on Human Health Detailed Quantitative Risk Assessment for Chemicals (DQRA Chem); Health Canada: Ottawa, ON, Canada, 2010.

29. United States Environmental Protection Agency (US EPA). Risk Assessment Guidance for Superfund: Volume III-Part A, Process for Conducting Probabilistic Risk Assessment; EPA: Washington, DC, USA, 2001.

30. European Food Safety Authority. Scientific Opinion on the Risk for Public Health Related to the Presence of Mercury and Methylmercury in Food; European Food Safety Authority: Parma, Italy, 2012.

31. Hinck, J.E.; Schmitt, C.J.; Chojnacki, K.A.; Tillitt, D.E. Environmental contaminants in freshwater fish and their risk to piscivorous wildlife based on a national monitoring program. Environ. Monit. Assess. 2009, 152, 469-494. [CrossRef]

32. Hoekstra, P.F.; O'Hara, T.M.; Backus, S.M.; Hanns, C.; Muir, D.C.G. Concentrations of persistent organochlorine contaminants in bowhead whale tissues and other biota from northern Alaska: Implications for human exposure from a subsistence diet. Environ. Res. 2005, 98, 329-340. [CrossRef] [PubMed]

33. Health Canada Mercury in Fish. Available online: https://www.canada.ca/en/health-canada/services/food-nutrition/foodsafety/chemical-contaminants/environmental-contaminants/mercury/mercury-fish.html (accessed on 10 February 2020).

34. Richardson, G.M.; Stantec Consulting Ltd. Canadian Exposure Factors Handbook; Toxicology Centre, University of Saskatchewan: Saskatoon, SK, Canada, 2013.

35. Palaniyandi, S. Determining Mercury and Selenium In Vitro Bioaccessibility in Country Foods Collected from Nunavik, Québec; University of Waterloo: Waterloo, ON, Canada, 2016.

36. Laird, B.D.; Goncharov, A.B.; Egeland, G.M.; Chan, H.M. Dietary advice on inuit traditional food use needs to balance benefits and risks of mercury, selenium, and n3 fatty acids. J. Nutr. 2013, 143, 923-930. [CrossRef] [PubMed]

37. Afonso, C.; Costa, S.; Cardoso, C.; Oliveira, R.; Lourenço, H.M.; Viula, A.; Batista, I. Benefits and risks associated with consumption of raw, cooked, and canned tuna (Thunnus spp.) based on the bioaccessibility of selenium and methylmercury. Environ. Res. 2015, 143 Part B, 130-137. [CrossRef]

38. Liao, W.; Zhao, W.; Wu, Y.; Rong, N.; Liu, X.; Li, K.; Wang, G. Multiple metal(loid)s bioaccessibility from cooked seafood and health risk assessment. Environ. Geochem. Health 2020, 9. [CrossRef] 
39. Yassine, R. Mercury Bioavailability in Traditional Food and the Effect of Selenium. University of Ottawa: Ottawa, ON, Canada, 2017.

40. Laird, B.D.; Shade, C.; Gantner, N.; Chan, H.M.; Siciliano, S.D. Bioaccessibility of mercury from traditional northern country foods measured using an in vitro gastrointestinal model is independent of mercury concentration. Sci. Total Environ. 2009, 407, 6003-6008. [CrossRef]

41. Burger, J.; Dixon, C.; Boring, S.; Gochfield, M. Effect of deep-frying fish on risk from mercury. J. Toxicol. Environ. Health Part A 2003, 66, 817-828. [CrossRef] [PubMed]

42. Costa, S.; Afonso, C.; Cardoso, C.; Batista, I.; Chaveiro, N.; Nunes, M.L.; Bandarra, N.M. Fatty acids, mercury, and methylmercury bioaccessibility in salmon (Salmo salar) using an in vitro model: Effect of culinary treatment. Food Chem. 2015, 185, 268-276. [CrossRef]

43. Morgan, J.N.; Berry, M.R.; Graves, R.L. Effects of commonly used cooking practices on total mercury concentration in fish and their impact on exposure assessments. J. Expo. Anal. Environ. 1997, 7, 119-133.

44. Moses, S.K.; Whiting, A.V.; Bratton, F.R.; Taylor, R.J.; O'Hara, T.M. Inorganic nutrients and contaminants in subsistence species of Alaska: Linking wildlife and human health. Int. J. Circumpolar Health 2009, 68, 53-74. [CrossRef]

45. Vincent, C. Retorting Machinery for the Manufacture of Heat-sterilised Fish Products. In Fish Canning Handbook; Wiley-Blackwell: Worcester, UK, 2010; pp. 179-209.

46. Costa, F.D.N.; Korn, M.G.A.; Brito, G.B.; Ferlin, S.; Fostier, A.H. Preliminary results of mercury levels in raw and cooked seafood and their public health impact. Food Chem. 2016, 192, 837-841. [CrossRef]

47. Costa, S.; Afonso, C.; Bandarra, N.M.; Gueifão, S.; Castanheira, I.; Carvalho, M.L.; Cardoso, C.; Nunes, M.L. The emerging farmed fish species meagre (Argyrosomus regius): How culinary treatment affects nutrients and contaminants concentration and associated benefit-risk balance. Food Chem. Toxicol. 2013, 60, 277-285. [CrossRef]

48. Maulvault, A.L.; Machado, R.; Afonso, C.; Lourenço, H.M.; Nunes, M.L.; Coelho, I.; Langerholc, T.; Marques, A. Bioaccessibility of $\mathrm{Hg}, \mathrm{Cd}$ and As in cooked black scabbard fish and edible crab. Food Chem. Toxicol. 2011, 49, 2808-2815. [CrossRef]

49. R Core Team. R: A Language and Environment for Statistical Computing; R Foundation for Statistical Computing: Vienna, Austria, 2020.

50. Afonso, C.; Costa, S.; Cardoso, C.; Bandarra, N.M.; Batista, I.; Coelho, I.; Castanheira, I.; Nunes, M.L. Evaluation of the risk/benefit associated to the consumption of raw and cooked farmed meagre based on the bioaccessibility of selenium, eicosapentaenoic acid and docosahexaenoic acid, total mercury, and methylmercury determined by an in vitro digestion mo. Food Chem. 2015, 170, 249-256. [CrossRef]

51. Afonso, C.; Costa, S.; Cardoso, C.; Coelho, I.; Castanheira, I.; Lourenço, H.; Gonçalves, S.; Oliveira, R.; Carvalho, M.L.; Martins, M.F.; et al. Bioaccessibility in risk-benefit analysis of raw and cooked seabream consumption. J. Food Compos. Anal. 2018, 68, 118-127. [CrossRef]

52. Cano-Sancho, G.; Perelló, G.; Maulvault, A.L.; Marques, A.; Nadal, M.; Domingo, J.L. Oral bioaccessibility of arsenic, mercury and methylmercury in marine species commercialized in Catalonia (Spain) and health risks for the consumers. Food Chem. Toxicol. 2015. [CrossRef] [PubMed]

53. Matos, J.; Lourenço, H.M.; Brito, P.; Maulvault, A.L.; Martins, L.L.; Afonso, C. Influence of bioaccessibility of total mercury, methyl-mercury and selenium on the risk/benefit associated to the consumption of raw and cooked blue shark (Prionace glauca). Environ. Res. 2015, 143, 123-129. [CrossRef]

54. Siedlikowski, M.; Bradley, M.; Kubow, S.; Goodrich, J.M.; Franzblau, A.; Basu, N. Bioaccessibility and bioavailability of methylmercury from seafood commonly consumed in North America: In vitro and epidemiological studies. Environ. Res. 2016, 149, 266-273. [CrossRef]

55. Wang, H.S.; Xu, W.F.; Chen, Z.J.; Cheng, Z.; Ge, L.C.; Man, Y.B.; Giesy, J.P.; Du, J.; Wong, C.K.C.; Wong, M.H. In vitro estimation of exposure of Hong Kong residents to mercury and methylmercury via consumption of market fishes. J. Hazard. Mater. 2013, 248-249, 387-393. [CrossRef]

56. Lescord, G.L.; Johnston, T.A.; Branfireun, B.A.; Gunn, J.M. Percent methylmercury in the muscle tissue of freshwater fish varies with body size, age, and among species. Environ. Toxicol. Chem. 2018, 37, 2682-2691. [CrossRef]

57. Lemes, M.; Wang, F.; Stern, G.A.; Ostertag, S.K.; Chan, H.M. Methylmercury and selenium speciation in different tissues of beluga whales (Delphinapterus leucas) from the western Canadian Arctic. Environ. Toxicol. Chem. 2011, 30, 2732-2738. [CrossRef]

58. Wagemann, R.; Trebacz, E.; Boila, G.; Lockhart, W.L. Methylmercury and total mercury in tissues of arctic marine mammals. Sci. Total Environ. 1998, 218, 19-31. [CrossRef]

59. Charette, T.; Bueno Dalto, D.; Rosabal, M.; Matte, J.J.; Amyot, M. Assessment of in vitro bioaccessibility and in vivo oral bioavailability as complementary tools to better understand the effect of cooking on methylmercury, arsenic, and selenium in tuna. Toxics 2021, 9, 27. [CrossRef] [PubMed]

60. Brodkorb, A.; Egger, L.; Alminger, M.; Alvito, P.; Assunção, R.; Ballance, S.; Bohn, T.; Bourlieu-Lacanal, C.; Boutrou, R.; Carrière, F.; et al. INFOGEST static in vitro simulation of gastrointestinal food digestion. Nat. Protoc. 2019, 14, 991-1014. [CrossRef]

61. Charette, T.; Rosabal, M.; Amyot, M. Mapping metal (Hg, As, Se), lipid and protein levels within fish muscular system in two fish species (Striped Bass and Northern Pike). Chemosphere 2021, 265, 129036. [CrossRef]

62. Health Canada. Part V: Guidance on Human Health Detailed Quantitative Risk Assessement for Chemicals (DQRA Chem); Health Canada: Ottawa, ON, Canada, 2010. 
63. Gaudin Laberge, V.; Receveur, O.; Walz, L.; Girard, F.; Potvin, L. A mixed methods inquiry into the determinants of traditionnal food consumption among three Cree communities of Eeyou Istchee from an ecological perspective. Int. J. Circumpolar Health 2014. [CrossRef]

64. Legrand, M.; Feeley, M.; Tikhonov, C.; Schoen, D.; Li-Muller, A. Methylmercury blood guidance values for Canada. Can. J. Public Health 2010, 101, 28-31. [CrossRef]

65. Watzl, B.; Gelencsér, E.; Hoekstra, J.; Kulling, S.; Lydeking-Olsen, E.; Rowland, I.; Schilter, B.; van Klaveren, J.; Chiodini, A. Application of the BRAFO-tiered approach for benefit-risk assessment to case studies on natural foods. Food Chem. Toxicol. 2012, 50, S699-S709. [CrossRef]

66. Van Oostdam, J.; Donaldson, S.G.; Feeley, M.; Arnold, D.; Ayotte, P.; Bondy, G.; Chan, L.; Dewaily, É.; Furgal, C.M.; Kuhnlein, H.; et al. Human health implications of environmental contaminants in Arctic Canada: A review. Sci. Total Environ. 2005, 351-352, 165-246. [CrossRef] 